\title{
Entrevista: O coração da liderança
}

Juliana Silveira

A irlandesa Linda McLoughlin criou a empresa de consultoria em liderança Linda McLoughlin LeadershipWorks, depois de mais de 20 anos no serviço público irlandês, onde trabalhou na Agência Estatal de Turismo (Cert) desenvolvendo currículos nacionais para apoiar a educação vocacional e a formação no setor turístico, além de ser responsável pela avaliação e certificação da indústria hoteleira

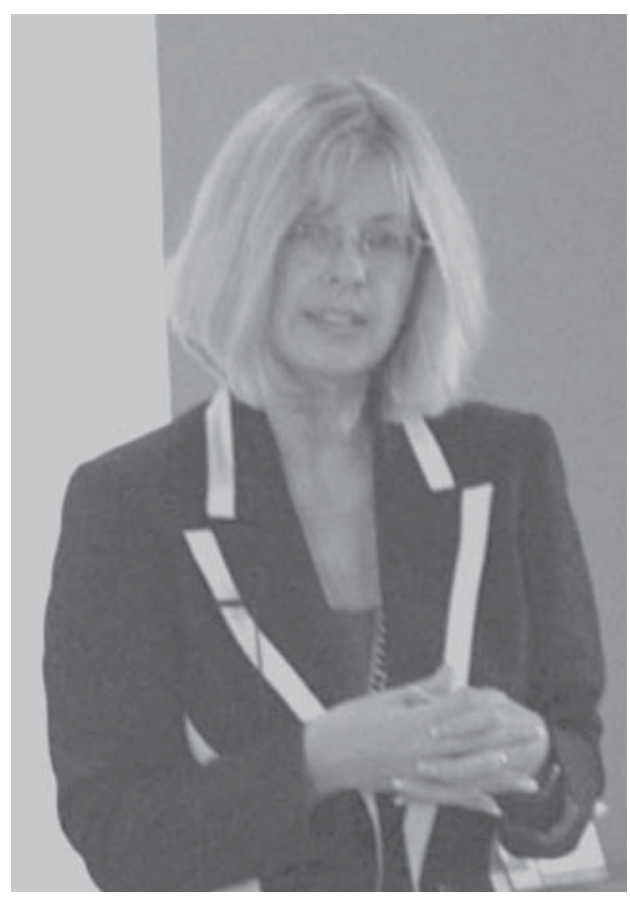
irlandesa. Em 1997, tornou-se, no Instituto de Administração Pública (Ipa), especialista em liderança e gestão sênior, e na Kennedy School of Government, em Harvard, desenvolveu pesquisa em percepções sobre liderança feminina no setor público. Com experiência em desenvolvimento de lideranças na Europa e na África, Linda McLoughlin visitou a ENAP, em setembro. Entre outras atividades, esteve à frente do Café com Debate, que contou com a participação da ministra Nilcéia Freire, da Secretaria 
Especial de Políticas paraas Mulheres, e de Magali Naves, representando a ministra Matilde Ribeiro, da Secretaria de Promoção da Igualdade Racial. Linda McLoughlin concedeu esta entrevista à Revista do Serviço Público:

\section{público?}

RSP: Como a liderança pode impactar o setor

Linda: O estudo "Liderança no século XXI”, da Organização para Cooperação e Desenvolvimento Econômico (OCDE), publicado em 2001, indica que a liderança é mais importante, especialmente, sob três condições. A primeira é quando se tem uma sociedade muito heterogênea. O Brasil é muito heterogêneo na sua composição étnica e a Irlanda está ficando cada vez mais. Tivemos, por muito tempo, uma população estável, mas, com o crescimento econômico, estamos atraindo trabalhadores imigrantes de outras culturas. Dessa forma, a liderança é importante para prover serviços públicos em uma sociedade heterogênea, de modo a assegurar inclusão social e eqüidade. É também importante em governos descentralizados porque a tendência no setor público é tornar a administração mais próxima do cidadão e do público. Nessas situações, requer-se que os administradores locais tenham mais liderança e sejam capazes de tomar decisões; de fato, a hierarquia não tem muita influência em uma situação descentralizada. A terceira condição é que, durante períodos de reforma e modernização, os líderes estejam aptos a administrar o processo de mudança e sejam criativos e inovadores para pensar em reengenharia e redesenho dos serviços públicos, de forma a agregar valor ao investimento e tornaremse sensíveis às necessidades dos cidadãos. Os líderes, em tempo de reformas, precisam mobilizar as equipes para implementar novas formas de trabalhar. Na Irlanda estamos passando por um período sustentável de modernização, incluindo um programa de descentralização. Em uma revisão oficial dessas reformas, a questão principal que surgiu foi a de que precisávamos de uma liderança transformadora porque, mesmo que algumas mudanças estruturais tenham sido implementadas, a profunda mudança cultural que se requer para dar suporte às reformas não estava em evidência no serviço público. Precisamos de líderes que possam inspirar e inovar, se realmente queremos que o processo de modernização seja firme e se torne mais que uma reforma cosmética ou superficial. Também precisamos de líderes em todos os níveis do serviço público deve-se passar além de hierarquias, de forma que as organizações possam empoderar suas equipes na linha de frente para tomar decisões e usar sua iniciativa na provisão de serviços mais responsivos e rápidos. A liderança está no coração da reforma e da excelência do serviço público.

RSP: Como os resultados da sua pesquisa podem ajudar o governo irlandês a lidar com o desenvolvimento de lideranças?

Linda: Penso que seja útil para os tomadores de decisão no momento, pois ela destaca onde estão os déficits de liderança e de competências de gerenciamento, uma vez que a ferramenta que utilizei para coletar os dados permite olhar para o comportamento dos líderes por meio de 22 diferentes dimensões. Posso ver tendências emergindo de padrões de comportamento porque tenho coletado dados há sete anos. É interessante notar que o perfil do dirigente no serviço público irlandês de fato não mudou nesse período, apesar da retórica da necessidade de mais liderança. Ainda não vemos muito do comportamento inovador, persuasivo, 
inspirador; sequer temos muito foco na produtividade e nos resultados, entre os líderes. A liderança é chave para mobilizar pessoas em torno da noção de mudança, mas os resultados da minha pesquisa são frustrantes. Sugerem que, apesar do investimento em treinamento e de se falar da necessidade de liderança, o desempenho dos gerentes públicos irlandeses carece de forte liderança e de orientação inovadora. Não é que não haja servidores que sejam líderes notáveis, mas precisamos desenvolver a capacidade de liderar através do sistema. Ainda vemos a predominância de um estilo mais burocrático de administração. A pesquisa mostra onde estão os déficits e onde, no futuro, devemos oferecer treinamento customizado de forma a desenvolver as competências requeridas para completar o processo de modernização. Atualmente, o governo irlandês convidou a OCDE para iniciar uma revisão oficial completa de nosso setor público, com ênfase particular em qualidade da liderança. É um empreendimento estimulante. Imagino que, após a revisão, haja renovado interesse no desenvolvimento de lideranças.

RSP: A pesquisa tem conseguido influenciar o modo como os cursos de capacitação são desenhados para o setor público irlandês?

Linda: Sim, ela serviu de base para muitos cursos, como os direcionados a dirigentes da área de saúde, a gerentes intermediários de governos locais com alto potencial para se tornarem dirigentes, a gestores. Em relação aos programas inovadores, a pesquisa definiu seu conteúdo e o foco de treinamento, bem como guiou o desenho geral do programa. Por exemplo, mostrou que os dirigentes acham o coaching executivo interessante; que o diagnóstico de $360^{\circ}$ ajuda bastante; que os cursos que estimulam a formação de redes são positivos. Então, fomos capazes de elaborar o desenho dos cursos em torno desses conceitos e nos afastamos de uma abordagem mais tradicional, que seria mais pesada em conteúdo e muito focada no tutor, no palestrante ou no fato de o professor ter todas as respostas prontas. É importante que o treinamento espelhe a mudança de comportamento que ele visa criar. Se queremos ver os gerentes mais pró-ativos, criativos e influentes em suas abordagens, então o desenho do conteúdo do programa deve ser não tradicional, desafiador e questionador. Uma pesquisa como essa pode prover a rationale para uma nova abordagem em treinamento e desenvolvimento.

\section{“A liderança está no coração da reforma $\mathrm{e}$ da excelência do serviço público."}

RSP: Os irlandeses tiveram uma mulher presidente da República, Mary Mc Aleese, sucedendo a primeira mulher presidente da Irlanda, Mary Robinson. Há diferença, no setor público irlandês, de percepção e comportamento em relação a mulheres no poder?

Linda: Essa é uma questão interessante. Eu realmente gostaria de poder ter uma resposta boa e clara. Até agora, tivemos três mandatos femininos na Presidência, que são maravilhosos modelos e revigoraram o papel da Presidência na Irlanda. Em nosso sistema, o presidente é mais uma figura, com o primeiro-ministro tendo a maior parte do poder. Mas quando Mary Robinson tornou-se presidente e quando se seguiu de Mary McAleese, elas 
trouxeram a Presidência mais próxima das pessoas e expandiram seu papel de modo muito positivo. Seu impacto será grande no longo prazo e pode ser ainda cedo para vermos o real efeito no setor público devido à sua cultura tradicional e burocrática. Há um maior número de mulheres indicadas para cargos de chefia mais altos. Definitivamente, houve progresso - nos últimos meses duas mulheres competiram e foram nomeadas para três dos cargos máximos do serviço público - e agora

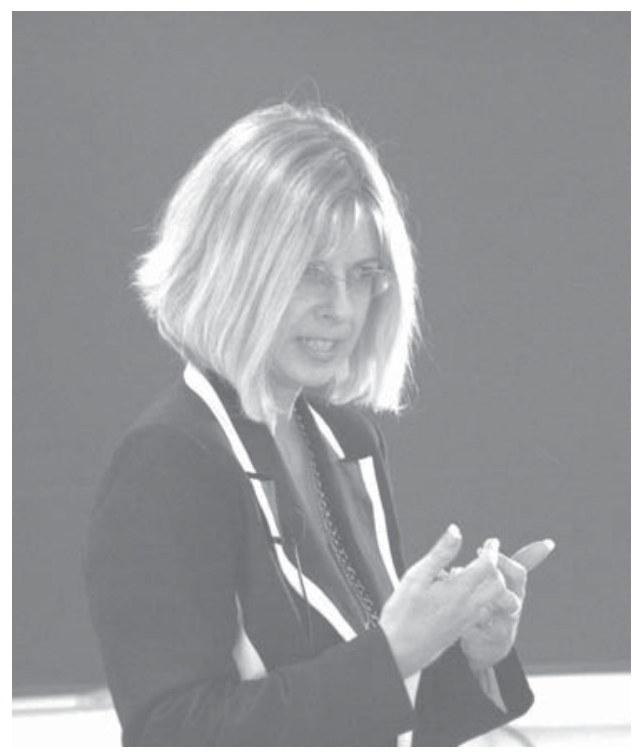

temos $1 / 3$ de representação feminina nesse nível, o que é uma melhoria significativa. Mas quando analisamos os salários de homens e mulheres irlandeses que têm o mesmo nível de escolaridade, vemos que os homens ainda ganham mais. Acho que isso sempre será uma questão para as mulheres, não importa o quão capazes elas sejam, o quão ambiciosas, ou que sejam boas líderes; como também é uma questão para as mulheres saber equilibrar seus compromissos familiares e sua carreira. Talvez, isso ainda não seja uma escolha tão difícil para os homens.
RSP: Como as mulheres podem preservar sua identidade e ajudar a tornar positivas as características femininas nas relações de poder?

Linda: Outra questão instigante! Acho que o jeito como a sociedade se organiza está mudando. Tenho notado, particularmente na Irlanda, que todo o processo de diálogo se torna cada vez mais importante, assim como o trabalho em parceria e a colaboração com as comunidades e outros grupos de cidadãos na entrega dos serviços públicos. Há novas estruturas e novas formas de se fazer negócio que requerem habilidades diferentes. As novas abordagens emergiram nos últimos cinco ou seis anos, particularmente em relação ao processo de consulta pública e ao trabalho em parceria.

Por exemplo, no passado, no setor público, decisões sobre onde uma nova rodovia seria construída, ou onde o aterro sanitário seria colocado, eram tomadas pela prefeitura. Nos últimos anos, as comunidades encontraram sua voz. Elas querem ser envolvidas nessas decisões, e então aumentaram os grupos de advocacy, particularmente, de questões ambientais, de política social, de saúde. Estou começando a considerar, uma vez que o modo de fazer negócio tem mudado de uma perspectiva muito incisiva "de alto a baixo" no modelo de tomada de decisão, que, quando isso mudar, de fato, as mulheres terão melhor desempenho porque têm know how para trabalhar em equipe e são orientadas para a colaboração. Talvez, com o passar do tempo, as características femininas sejam mais valorizadas. Não significa dizer que os homens não têm essas qualidades, mas, se consideramos que somos mais intuitivas, mais emocionalmente inteligentes, podemos começar a redefinir nosso conceito de efetividade gerencial. Isso pode criar novas oportunidades para as mulheres 
usarem seus talentos e validarem seus modos particulares de trabalhar e fazer negócio. Eu vejo isso acontecendo ao longo dos anos. O ideal seria ver a evolução de uma cultura do serviço público que valorizasse igualmente traços femininos e masculinos, e reconhecesse a importância da diversidade e das perspectivas diferentes.

RSP: Em seu estudo, são mencionados três tipos de fracasso de liderança: na aprendizagem, na responsabilidade e na falta de inteligência emocional. Como isso poderia explicar, à luz do seu estudo de percepções, a questão de as mulheres não serem reconhecidas como boas lideres pelo fato de expressarem mais livremente suas emoçoes?

Linda: Quando falei dos três tipos de fracasso de liderança, discutia em nível mais sistêmico. Estávamos olhando para um serviço público mais tradicional, que tem um modo já estabelecido de trabalhar e fazer as coisas. Dessa forma, uma das falhas é que os líderes não têm aprendido nem evoluído a partir de suas experiências prévias. Temos um sistema que não tende a dar importância à responsabilidade individual e à accountability. Assim, freqüentemente, o fracasso pode ser atribuído aos políticos, ao público, a qualquer um, menos ao verdadeiro responsável. Existe essa cultura, que não enfatiza de fato onde é o ponto final. Então, quando falei do fracasso da liderança em não tomar responsabilidade, isso se torna mais evidente no nível sistêmico.

Porém, com relação ao fracasso da inteligência emocional, características como autoconsciência e consideração pelos outros não têm sido valorizadas como um todo. O treinamento tradicional e a formação dos servidores públicos diziam respeito mais ao desenvolvimento cognitivo das pessoas. Eles eram bons em análises, em formulação de políticas, em administrar as expectativas dos políticos, em seguir instruções? Essas eram, provavelmente, as características que deveriam ser mais valorizadas em um servidor público, em vez da empatia, compreensão e motivação, no nível sistêmico. Penso que as mulheres são tão culpadas por esses fracassos quanto os homens. Não podemos dizer "é tudo culpa dos

homens" porque sempre tivemos participação significativa no serviço público, que é o maior empregador de mulheres. Apenas não temos visto mais mulheres em posições de alto mando, mas isso está mudando. Quanto à segunda parte da questão, os resultados da pesquisa do estudo do Management Research Group (MRG) mostraram que nos níveis mais seniores não havia, virtualmente, nenhuma diferença na percepção do desempenho dos homens e das mulheres dirigentes os mais hábeis e os mais estratégicos chegaram lá. Nos níveis mais baixos, entretanto, havia uma diferença de percepção e eu enfatizo que era uma percepção, e não um resultado baseado no desempenho de fato. O que o estudo 
mostrou foi que os chefes tendem a ver seus pares masculinos como mais contidos, capazes de trabalhar sob pressão, mais firmes e tendentes a usar uma abordagem tradicional para resolver problemas. No entanto, os chefes tendem a ver suas colegas fazendo menos esforço para controlar suas emoções, expressando o que pensam e sentem, e colocando mais ênfase no estabelecimento de metas, nomonitoramento e na observação de prazos. O interessante é notar que os subordinados de gerentes homens e mulheres faziam pouca distinção e tendiam a julgar cada gerente simplesmente com base em seu desempenho no trabalho. De novo, aqui é que mecanismos mais robustos de recrutamento e promoção são importantes para garantir que os vieses pessoais ou percepções não tenham influência indevida nos prospectos de carreira de mulheres gerentes. Na Irlanda, estamos adotando entrevistas baseadas em competências, que é um modo mais justo e transparente para todos os interessados. A principal recomendação do estudo do MRG é que as mulheres líderes realmente precisam desenvolver fortes habilidades de planejamento estratégico como o melhor caminho para chegar ao topo, e isso deve ser incorporado por aqueles responsáveis pelo desenho e pela oferta de desenvolvimento gerencial e de liderança para os servidores públicos. Tem sido largamente reconhecido que níveis maiores de inteligência emocional são a essência da liderança, de modo que podemos esperar que isso seja cada vez mais valorizado entre os servidores públicos. 